University of Wollongong

Research Online

Faculty of Social Sciences - Papers (Archive) Faculty of Arts, Social Sciences \& Humanities

2013

Monitoring the availability of healthy and unhealthy foods and nonalcoholic beverages in community and consumer retail food environments globally

C N. Mhurchu

University of Auckland

S Vandevijvere

University of Auckland

W Waterlander

University of Auckland

L E. Thornton

Deakin University

Bridget Kelly

University of Wollongong, bkelly@uow.edu.au

See next page for additional authors

Follow this and additional works at: https://ro.uow.edu.au/sspapers

Part of the Education Commons, and the Social and Behavioral Sciences Commons

Research Online is the open access institutional repository for the University of Wollongong. For further information contact the UOW Library: research-pubs@uow.edu.au 


\title{
Monitoring the availability of healthy and unhealthy foods and non-alcoholic beverages in community and consumer retail food environments globally
}

\begin{abstract}
Retail food environments are increasingly considered influential in determining dietary behaviours and health outcomes. We reviewed the available evidence on associations between community (type, availability and accessibility of food outlets) and consumer (product availability, prices, promotions and nutritional quality within stores) food environments and dietary outcomes in order to develop an evidencebased framework for monitoring the availability of healthy and unhealthy foods and non-alcoholic beverages in retail food environments. Current evidence is suggestive of an association between community and consumer food environments and dietary outcomes; however, substantial heterogeneity in study designs, methods and measurement tools makes it difficult to draw firm conclusions. The use of standardized tools to monitor local food environments within and across countries may help to validate this relationship. We propose a step-wise framework to monitor and benchmark community and consumer retail food environments that can be used to assess density of healthy and unhealthy food outlets; measure proximity of healthy and unhealthy food outlets to homes/schools; evaluate availability of healthy and unhealthy foods in-store; compare food environments over time and between regions and countries; evaluate compliance with local policies, guidelines or voluntary codes of practice; and determine the impact of changes to retail food environments on health outcomes, such as obesity.
\end{abstract}

\section{Keywords}

food, retail, consumer, community, beverages, globally, alcoholic, environments, non, foods, unhealthy, healthy, availability, monitoring

\section{Disciplines}

Education | Social and Behavioral Sciences

\section{Publication Details}

Ni Mhurchu, C., Vandevijvere, S., Waterlander, W., Thornton, L. E., Kelly, B., Cameron, A. J., Snowdon, W. \& Swinburn, B. (2013). Monitoring the availability of healthy and unhealthy foods and non-alcoholic beverages in community and consumer retail food environments globally. Obesity Reviews, 14 (Suppl. S1), 108-119.

\section{Authors}

C N. Mhurchu, S Vandevijvere, W Waterlander, L E. Thornton, Bridget Kelly, A J. Cameron, W Snowdon, and Boyd A. Swinburn 


\title{
Review
}

\section{Monitoring the availability of healthy and unhealthy foods and non-alcoholic beverages in community and consumer retail food environments globally}

\author{
C. Ni Mhurchu¹, S. Vandevijvere², W. Waterlander ${ }^{1}$, L. E. Thornton ${ }^{3}$, B. Kelly, A. J. Cameron ${ }^{3}$, \\ W. Snowdon ${ }^{5,6}$ and B. Swinburn ${ }^{2,6}$ for INFORMAS^
}

\author{
'National Institute for Health Innovation, \\ University of Auckland, Auckland, New \\ Zealand; ${ }^{2}$ School of Population Health, \\ University of Auckland, Auckland, New \\ Zealand; ${ }^{3}$ Centre for Physical Activity and \\ Nutrition Research, Deakin University, \\ Melbourne, Australia; ${ }^{4}$ School of Health and \\ Society, University of Wollongong, \\ Wollongong, New South Wales, Australia: \\ ${ }^{5}$ Pacific Research Centre for the Prevention of \\ Obesity and Non-communicable Diseases \\ (C-POND), Suva, Fiji; ${ }^{6}$ WHO Collaborating \\ Centre for Obesity Prevention, Deakin \\ University, Victoria, Australia
}

Address for correspondence: C Ni Mhurchu, National Institute for Health Innovation, University of Auckland, Private Bag 92019, Auckland 1142, New Zealand.

E-mail: c.nimhurchu@nihi.auckland.ac.nz

\begin{abstract}
Summary
Retail food environments are increasingly considered influential in determining dietary behaviours and health outcomes. We reviewed the available evidence on associations between community (type, availability and accessibility of food outlets) and consumer (product availability, prices, promotions and nutritional quality within stores) food environments and dietary outcomes in order to develop an evidence-based framework for monitoring the availability of healthy and unhealthy foods and non-alcoholic beverages in retail food environments. Current evidence is suggestive of an association between community and consumer food environments and dietary outcomes; however, substantial heterogeneity in study designs, methods and measurement tools makes it difficult to draw firm conclusions. The use of standardized tools to monitor local food environments within and across countries may help to validate this relationship. We propose a stepwise framework to monitor and benchmark community and consumer retail food environments that can be used to assess density of healthy and unhealthy food outlets; measure proximity of healthy and unhealthy food outlets to homes/ schools; evaluate availability of healthy and unhealthy foods in-store; compare food environments over time and between regions and countries; evaluate compliance with local policies, guidelines or voluntary codes of practice; and determine the impact of changes to retail food environments on health outcomes, such as obesity.
\end{abstract}

Keywords: Food access, food availability, food location, INFORMAS, retail food environment.

obesity reviews (2013) 14 (Suppl. 1), 108-119

\section{Background}

Retail food environments are considered influential in determining dietary behaviours and health outcomes $(1,2)$. The retail food environment can be divided into the community food environment (the type, availability and

ANFORMAS is the International Network for Food and Obesity/noncommunicable diseases Research, Monitoring and Action Support. accessibility of food outlets) and the consumer food environment (the availability, prices, promotions and nutritional quality of products available within stores) (3).

As evidence emerges of the relationship between food environments and eating behaviours, initiatives to improve food environments are increasing. In 2008, the Los Angeles City Council, in the United States (USA), approved a 1-year moratorium on the opening of new fast food establishments in several south Los Angeles neighbourhoods with 
high fast food density and high obesity $(4,5)$. In Detroit, USA, the zoning code prohibits the building of fast food restaurants within $500 \mathrm{ft}$ of all elementary, junior and senior high schools (6). Other examples include South Korea's 'Green Food Zones' where sales of unhealthy foods are restricted within a 200-m radius of schools (7), and regional enterprises to improve community access to fresh fruit and vegetables $(8,9)$. However, there are no established systems to monitor and evaluate the impact of such initiatives.

Effective monitoring of retail food environments enables: (i) classification of areas or neighbourhoods with regard to access and availability of healthy and unhealthy foods; (ii) comparisons between jurisdictions and regions; (iii) identification of changes over time; (iv) appropriate targeting of programmes to improve local food environments; and (v) evaluation of the impact of retail food environments on health outcomes, including obesity.

The International Network for Food and Obesity/noncommunicable diseases Research, Monitoring and Action Support (INFORMAS) is a global network of publicinterest organizations and researchers that aims to monitor, benchmark and support public- and private-sector actions to create healthy food environments and reduce obesity, non-communicable diseases and their inequalities (10). This INFORMAS module focuses on the availability of healthy and unhealthy foods and non-alcoholic beverages in retail food environments. The module seeks to answer the research question: 'What is the availability of healthy and unhealthy foods and non-alcoholic beverages in communities and within retail outlets?' The aim of this paper was to develop an evidence-based framework for monitoring community and consumer food environments globally, based on a review of the available evidence on associations between consumer and community food environments and dietary outcomes (in two separate reviews).

\section{Review of community retail food environment studies}

A systematic search was conducted to identify studies of any design (observational or experimental) published in English that investigated associations between availability/ density of, or accessibility/proximity to, food outlets (including supermarkets, grocery stores, convenience stores, fast food and quick-service restaurants, and fresh food/farmers' markets), and: (i) measured or self-reported food purchases; or (ii) dietary intake (consumption of foods and/or nutrients measured using any method of dietary assessment). Studies from all countries and among all age groups, published until 31 December 2012, were eligible for inclusion. Medline and Embase databases were searched using keywords ( ( (supermarket OR shop OR store OR mall OR drive-in OR eating place OR food outlet
OR market OR restaurant OR outlet OR retail* OR grocer* OR food environment) AND (density OR proximity OR distance OR remoteness OR access) AND (purchas* OR shop* OR acquisition OR acquir* OR buy OR diet OR consum* OR intake OR eat* OR obes* OR overweight OR body mass index OR weight) ) OR (food desert OR food deserts) ). Bibliographies of relevant review papers and key publications were scanned to identify additional appropriate studies. Studies using both subjective (perception surveys) and objective (spatial measures) methods to assess characteristics of the community food environment were included.

We excluded market basket studies evaluating the cost of healthy foods (11) and those investigating in-store characteristics (reviewed separately in this paper). Studies that investigated community socioeconomic position, poverty or racial segregation as environmental measures were also excluded. Our focus was the relationship between retail food environment components as exposures and food purchasing/diet as outcomes. Therefore, we excluded studies that described exposure only (no outcomes).

Existing relevant systematic reviews $(12,13)$ were summarized and supplemented with new studies identified by our systematic search. For simplicity, findings are presented first for the impact of the retail food environment on food purchasing behaviours (proximal effect) and subsequently for dietary intake (more distal effect).

\section{Community food environments and food purchasing behaviour}

Seven studies were identified that examined relationships of food outlet availability/accessibility with food purchasing behaviour, all of which were cross-sectional, from developed countries (United States, Canada, Australia), and published in the period 2009-2012 (Supporting Information Table S1) (14-20). Most studies assessed the frequency of food purchases from various types of food outlets as the outcome measure, although one looked specifically at the frequency of sugar-sweetened beverage purchases and another at the variety of fruit and vegetable purchases. Three of the seven studies reported significant positive associations between density of food outlets and food purchases $(15,16,18)$, while two of four studies reported significant positive associations between proximity to food outlets and food purchasing $(15,19)$.

Two studies examined environments around homes and schools $(15,17)$. One found significant associations between density of fast food outlets around both homes and schools and fast food purchasing frequency (15). However, significant associations between proximity of fast food outlets and purchasing behaviour were only found for retail food environment around homes (15). One study measured both absolute density of healthy food outlets and density relative to density of unhealthier food outlets, 
finding a stronger positive association between relative density of healthy food outlets and healthy purchasing behaviour than for absolute density (18). Thus, it appears important to focus not just on how much healthy food is available in a neighbourhood, but also its availability relative to unhealthy food.

\section{Community food environments and dietary intake}

A number of systematic reviews have investigated the relationship between the community food environment and diet $(12,13,21,22)$. The most recent review included 38 papers published up to March 2011 (12). Overall, 24 studies were U.S.-based, and the remainder were from other high-income countries. Most used a cross-sectional design, but two were natural experiments $(23,24)$.

Our own systematic search retrieved 19 additional studies published after March 2011 (25-43) (Supporting Information Table S2), of which 11 were from the United States, seven from non-U.S. high-income countries, and two from low- or middle-income countries (Brazil and China) $(34,43)$. Most newly identified studies were cross-sectional, but one was ecological and two were longitudinal.

Both longitudinal studies and the ecological study found significant associations between availability of retail food outlets and diet $(26,34,43)$. Two natural experiments, which explored the effects of opening a new supermarket on dietary behaviour, were conducted in the United Kingdom. One showed no change in fruit and vegetable consumption between intervention and control groups (23), and the other reported that fruit and vegetable consumption increased among residents who switched stores, lived closest to the new store, and had the lowest consumption at baseline, although there was no increase in fruit and vegetable consumption overall (24).

Studies using measures of residents' perceived food availability were consistent in showing a relationship with dietary outcomes. Findings from the 35 studies that used objective measures of store presence, store density or store variety were however mixed. Twenty-four studies showed a significant association between food outlet availability and dietary outcomes in the expected direction while one found an association in the opposite direction (44).

Of 22 studies that examined proximity to food stores in relation to diet, 13 reported null associations. In one study that reported a positive association between proximity to food stores and diet, store access was operationalized as a multifaceted combination of variables, including car access, where participants shopped and travel time (45).

Studies using self-reported measures of the food environment consistently reported small, but meaningful differences in fruit and vegetable consumption $(45,46)$, while results for objective measures were not always meaningful from a public health perspective. For example, one study among seniors showed that being one mile in distance further from a supermarket was associated with a statistically significant, but nutritionally unimportant difference of 0.02 less servings of fruit and vegetables a day (47).

\section{Methods and instruments for measuring community food environments}

Both subjective (perception surveys) and objective (spatial measures) methods may be used to assess characteristics of the community food environment (48). Data collection can be performed using primary (surveys among individuals or direct observations) or secondary methods (e.g. via Yellow Pages or commercial data) (49).

Density of food outlets can be measured within a defined geographic area or using the buffer method, kernel density method or spatial clustering (defined in Table 3). Buffer distances used vary widely from $100 \mathrm{~m}$ to $3.2 \mathrm{~km}$ ( 2 miles) $(50,51)$. Densities can be expressed simply as the count of outlets within a specified area or in relative terms as the number of outlets per 10,000 people or per square kilometre (49). Global positioning system (GPS) tracks have also been used to define the community environment for individuals, where food locations within half a mile of participants' GPS tracks were identified (52).

Proximity to food outlets can be measured by distance (Euclidean, Manhattan or network distance by road), travel time, or presence or absence of an outlet within a specified distance from any origin of interest (e.g. home or schools). Travel time can take into account the means of transport (car, bus, foot) and the specifics of the network (e.g. road type, speed limit, barriers as rivers or railway lines, or frequency of buses) (48). In general, modelling of travel time seems to lead to more realistic measurements than calculation of distances alone, especially in submetropolitan (53) or rural (54) areas.

\section{Limitations of current techniques}

Defining a neighbourhood is complex and geographic boundaries set using geographical information systems (GIS) may not adequately operationalize the true space where people live and interact (55). Almost all published research operates under the assumption that people use what is geographically proximate. Yet a study of shopping behaviour showed that low-income residents in urban areas rarely shopped at the closest supermarket and did much of their grocery shopping outside their own neighbourhood (56). Defining an appropriately sized area around places of residence further depends on age group, type of food outlet of interest, and type of transportation. There is a lack of criteria for determining suitable buffer distances $(57,58)$.

Data collected from secondary sources may misrepresent true geographic access, either by including stores that are no longer open, by missing stores entirely (59) or by listing outlets as an incorrect service type. Powell et al. (60) found only moderate agreement between commercial data and 
field observations for supermarkets, grocery stores, convenience stores and full-service restaurants, and poor agreement for fast food restaurants. Field studies by Bader et al. (61) and Liese et al. (59) found reasonably good predictive values, although there were important discrepancies. To ensure accuracy of secondary data sources, validation against primary data is advisable (49).

Following data acquisition, the process of geocoding (defined in Table 1) may also introduce errors (62,63). There might be a mismatch between the geocoded location of a facility and its true location, e.g. determined via the GPS technique $(62,64)$.

\section{Summary}

A large number of studies have measured availability of and/or access to food outlets in the community environment, using a variety of methods. The majority report at least one significant finding, but not all of the observed relationships are nutritionally significant. This evidence is suggestive of an association between community food environments and dietary habits. Almost no evidence regarding associations between the community food environment and diet exists from low- and middle-income countries.

Some research suggests it might be important to measure relative density of both healthy and unhealthy food outlets to accurately reflect the milieu of outlet types available to residents (e.g. communities that have an abundance of both supermarkets and fast food outlets). The use of quasiexperimental designs and natural experiments should be better exploited to assess health impacts following neighbourhood changes such as the introduction of new supermarkets and changes in zoning laws (65). A solid monitoring framework would support the capture of these data.

\section{Review of consumer retail food environments}

In-store promotion strategies follow the general marketing concept of the 4 Ps (price, placement, product, promotion) (66). Because the monitoring of food prices (11), product composition (67), promotions (68) and labelling (69) are covered by other INFORMAS modules, our review focused on product availability and product placement within food outlets. We included studies that investigated associations between either availability/density or location/placement of foods in outlets and: (i) measured or self-reported food purchases; or (ii) dietary intake.

The basis of our review was three recently published reviews (70-72) and two recent empirical studies $(73,74)$ on the consumer food environment. The bibliographies of these papers were scanned to identify relevant studies. This initial search revealed that there was little evidence regarding associations between in-store food environments and
Table 1 Concepts and terms used in relation to community food environments

\begin{tabular}{ll}
\hline Concept/term & Definition \\
\hline Availability & Adequacy of the supply of food (12) \\
Accessibility & The location of the food supply and the ease of \\
& getting to that location (determined by distance, \\
& travel time and costs, public transportation \\
& networks, private vehicle ownership, etc.) \\
& $(12,49,105)$
\end{tabular}

Geocoding

The process of matching raw address data with a digital spatial data set including all addresses within the area of interest mapped to latitude and longitude coordinates (49)

Geographical information systems

Computer-based tools, which, via different information sources, enable spatial and thematic data to be organized, managed and combined, and results to be represented and analysed according to geographic location (48)

Buffer

A zone around a given location (point [circular buffer]: home, school, food outlet; line [network buffer]: road; neighbourhood) within a specified distance or shape (48). One study used a sausage buffer, buffering $150 \mathrm{~m}$ on either side of each road out the distance of the buffer (30).

Kernel density method

A statistical method used to transform a sample of geographically referenced point data into a smooth continuous surface and to estimate the intensity of referenced point data across a surface, by calculating the overall number of cases situated within a given search radius from a target point (106). Points lying near the centre of the search area are weighted more heavily than those lying near the edge (48).

Spatial clustering

The creation of windows of various shapes and sizes moving systematically across the map to identify events that are likely more prevalent inside than outside a given window (48)

Euclidian distance

Straight line distance

Manhattan distance The distance between two points measured along axes at right angles

Food desert

Communities where residents cannot obtain affordable, healthy foods $(65,107)$. In the United States, the presence of a supermarket has been found to be a particularly important defining feature of food deserts (108). The definition of the concept of food deserts in an international setting is still under debate.

the healthiness of food purchases/diet, and a particular lack of intervention studies. Subsequently, we searched for more recent publications in PubMed and Google Scholar by identifying publications that cited the existing reviews/studies, retrieving them and scanning their bibliographies. In total, 13 studies were included in this review. We included all study designs. We present findings for both food purchasing and dietary outcomes combined. 


\section{Consumer food environment and food purchasing/dietary intakes}

A review by Gustafson et al. comprising 56 studies published from 2000 to 2011 focused on the association of the consumer food environment with neighbourhood characteristics, food prices, dietary patterns and weight status (71). Five studies examined the association between food availability in-store and dietary patterns specifically. Two of these examined perceived food availability only $(75,76)$. Another used structural equation modelling to identify the interplay of individual, social and environmental factors in relation to dietary fat intake (77). A fourth study investigated whether healthy and unhealthy dietary intakes were patterned by neighbourhood socioeconomic disadvantage (78). The final study examined associations between directly measured availability of healthy foods and diet quality (79). Gustafson et al. concluded that the consumer food environment was not consistently associated with dietary outcomes. However, inconsistency and complexity of methods used to determine the availability of foods within stores makes it difficult to draw conclusions regarding its influence on diet (71).

The review by Glanz et al. comprised 125 papers published between 1995 and 2010 on aspects of food marketing experienced by consumers in grocery stores (70). Studies included were classified according to: product (availability, variety, packaging design), price (elasticity, promotions), place (in-store location/aisle management) and promotion (displays, featured advertising, point-ofpurchase information). The authors noted that the ' 4 Ps' of marketing are not mutually exclusive, but typically occur in combinations such as product plus placement, or price plus promotion. Overall, there was limited evidence that increasing availability of healthy food products (products stocked and variety) in stores increased healthy eating (70). With respect to placement, the amount of shelf space and prominence of location (e.g. end of aisle) were found to be influential. It was suggested that interventions may have greater impact if they focus on altering the placement and promotion of less healthy foods, instead of merely increasing access to healthier options.

We identified 13 further relevant studies that looked specifically at relationships between food availability in-store and food purchasing behaviours or diet, covering the period 1972-2012 (Supporting Information Table S3) (74,79-94). Most studies were cross-sectional; three involved development/testing of marketing models; two were validation studies for in-store audit assessment tools; and three were experimental. Most assessed self-reported food purchases or dietary intake as outcome measures, but four studies assessed product sales $(82,83,86,93)$ and one assessed body mass index (BMI) (90).

A number of marketing studies undertaken in the $1970 \mathrm{~s}$ and 1980s examined how changes in product shelf space allocation impacted on sales $(82,83,86)$. One found that unit sales increased by approximately $8 \%$ in response to an increase in shelf space of $40 \%$ (82). Another study by the same author determined that increasing shelf space allocated to fruit and vegetables by $100 \%$ resulted in increases in sales of $29-59 \%$ (83). Hansen and Heinsbroek (86) developed a model to optimize supermarket product selection, shelf space and sales and reported that taking shelf space elasticity into account resulted in an appreciable increase in profits $(\sim 6 \%)$. In two marketing experiments, product shelf space (83) and displays (93) were manipulated and impacts on unit sales were assessed. Both shelf space and display level had significant effects on sales $(83,93)$. One study measured the aggregate availability of specific foods in a neighbourhood. Rose et al. measured linear shelf space allocated to fruits, vegetables and energydense snack foods in 307 food stores in Louisiana, USA and geocoded all stores in the broader area (90). They then estimated cumulative shelf space of foods within defined distances of study participants using observations from the in-store survey and probability-based assignments of shelf space to all unobserved stores in the area (90). Results showed that cumulative shelf space of energy-dense snack foods was positively associated with BMI. An additional $100 \mathrm{~m}$ in shelf space of these foods within $1 \mathrm{~km}$ of a participant's residency was associated with an additional 0.1 BMI points. However, fruit and vegetable shelf space was not significantly related to BMI (90). A store intervention in Hawaii, USA that included increased stocking of healthy foods, together with point-of-purchase promotions, led to significant improvements in the diets of children subject to the intervention (85).

\section{Methods and instruments for measuring the consumer food environment}

Studies measuring the consumer retail food environment use a range of tools that target different aspects of the in-store food environment. Some measures assess food availability, e.g. Nutrition Environment Measures Survey in Stores (NEMS-S), which measures availability, price and quality of 10 food categories $(79,95)$; while others assess product placement and promotions (GroPromo) (88), in-store displays $(74,87)$ and shelf space $(84,90)$. Some measures focus on snack foods (allocated shelf space and availability at checkouts (96-98)) while one audit tool assessed availability and variety of a wide range of foods (91). The reliability and validity of NEMS-S and GroPromo have been evaluated. Inter-rater reliability kappas of $0.84-1.00$ and test-retest reliability kappas of $0.73-1.00$ have been reported for NEMS-S (95). GroPromo was also found to have moderate to high inter-rater reliability (intraclass correlation $\geq 0.61$ ) $(88)$. Construct validity of the GroPromo instrument was tested by measuring proportional food purchases (using store customers' receipts) for 
each food category assessed; and strong relationships were observed between consumer expenditure on specific foods and in-store placement of products, including placement of unhealthy items in high-traffic areas, key locations and at end-of-aisles (88). There is also a NEMS tool to characterize restaurant environments (NEMS-R) (99), that measures the availability of healthy meals and products, facilitators of healthy eating (e.g. provision of nutrition information), barriers to healthy eating (e.g. encouraging large portion selection), pricing of healthy and unhealthy options, and non-menu marketing. NEMS-R was validated in a study of 217 restaurants in four neighbourhoods and was found to be reliable and could discriminate restaurant types. Another (non-validated) tool to measure restaurant environments was developed by Lewis et al. (100), and measures availability, quality and preparation of food as well as elements of the restaurant including cleanliness, promotions and quality of service.

\section{Summary}

A variety of methods exist to measure the consumer food environment. Current evidence is suggestive of an association between the consumer food environment and dietary outcomes; however, the variety and complexity of methods used to assess the availability of foods within stores makes it difficult to draw firm conclusions. The number of studies in this area is small and it is rare for studies across multiple contexts to utilize the same assessment methods (98). Further work is required to evaluate the relationship between consistent measures of the environment and dietary and other outcomes. All studies to date have been undertaken in English-speaking high-income countries and there is no evidence regarding the association between the consumer food environment and food purchases and/or diets in low- and middle-income countries. While current evidence regarding associations between the consumer food environment and health outcomes is only suggestive, marketing studies indicate that product shelf space and displays have significant effects on sales. When measuring the in-store food environment, it therefore appears important to measure these aspects of the environment. Finally, the study by Rose et al. (90) evaluating the aggregate linear shelf space of food types for a neighbourhood is an example of how measures of community and consumer retail food environments could be integrated to potentially more accurately represent the food environment experienced by neighbourhood residents.

\section{Proposed approach to monitoring retail food environments}

The proposed overall approach to monitoring and benchmarking food environments is outlined in detail in the INFORMAS overview paper (10). For each module, moni- toring frameworks have been developed that allow for step-wise approaches ('minimal', 'expanded' and 'optimal') to indicator selection and other monitoring features. Participating countries can select an approach based on local resources and capacity. Regular data collections are important to enable comparisons over time and timely evaluation of the impact of local policy initiatives.

A contextual analysis should be undertaken to determine local needs in relation to monitoring retail food environments and the level of data to be collected in individual countries. Key questions include: (i) Is there a large and/or increasing burden of diet-related diseases and/or obesity?; (ii) What are the key dietary risk factors for the population?; (iii) What are the major food sources for the population?; (iv) What kinds of food outlets are dominant or scarce?; (v) Is there any existing evidence on community and consumer retail food environments?; (vi) Has geocoding of food retail outlets and homes/schools been undertaken and are lists of food retail outlets readily available and sufficiently up-to-date?; (vii) Is GIS software and expertise available?; (viii) Are there existing national or local data collection surveys that could be utilized or built upon?; and (ix) Do the resources and expertise necessary to undertake such monitoring exist locally?

For each participating country, the regulatory and policy environment should be analysed in relation to food retail environments. Where government regulations and/or industry codes of practice exist regarding the availability and placement of food outlets and/or the availability and placement of foods within stores, the content and scope of such polices should be analysed. Examples include zoning policies to restrict fast food outlets around schools (7), and programmes to improve access to fresh fruit and vegetables in deprived areas/food deserts $(8,9)$. The absence of such policies or programmes should also be noted.

\section{Food sources/outlets to be monitored}

The monitoring framework suggested here has been developed with a view to ensuring that monitoring focuses on aspects of the retail food environment that are most policy relevant and amenable to change via policy response (by either the public or private sector). With that in mind, it is proposed that types of food sources/outlets to be monitored are those that account for the greatest proportion of local food consumption and/or for which evidence exists of an association with dietary outcomes. Examples include supermarkets, convenience stores, fast food restaurant chains, fresh produce markets and vending machines in some cases.

\section{Foods to be monitored}

The foods to be monitored should be able to be easily defined and should link clearly with risk of obesity and/or NCDs. These include healthy items such as fruits and vegetables (101); and unhealthy items such as sugar-sweetened 
beverages (102), energy-dense nutrient-poor foods (e.g. confectionery) (103), and fast foods (104). Final selection of specific foods to be monitored should be based on local food consumption data.

Based on our review of the literature, aspects of the retail food environment that may be important to monitor include: food source/outlet type, relative outlet density of healthy and unhealthy stores, availability of healthy and unhealthy foods and beverages in-store, shelf space allocated to specific foods/beverages, product placement (e.g. end-of-aisle, checkouts, number of locations), and displays.

\section{Monitoring framework}

We propose a step-wise monitoring framework comprising 'minimal', 'expanded' and 'optimal' approaches (Table 2). The minimal approach involves monitoring availability and accessibility of fresh fruits and vegetables and energy-dense nutrient-poor foods in one key retail outlet type (depending on contextual analysis) in a limited number of locations/ areas. The expanded approach is designed to assess a larger number of food outlet types in an increased number of geographical areas, and enables assessment of proximity to food outlets within school and residential areas. The optimal approach builds on the minimal and expanded approaches to capture a comprehensive picture of the relative density of all food outlets, their proximity to schools and homes, and availability/accessibility of healthy and unhealthy foods and beverages within stores.

It is recommended that monitoring of the community and consumer retail food environments be undertaken at regular intervals to enable timely assessment of changes over time and in response to policy interventions, and to facilitate tracking of relationships with population dietary behaviours over time. However, precise data collection intervals will vary according to local resources and capacity.

Table 2 Step-wise framework for monitoring and benchmarking retail food environments

\begin{tabular}{|c|c|c|}
\hline Minimal approach & Expanded approach & Optimal approach \\
\hline \multicolumn{3}{|l|}{ Food outlets } \\
\hline $\begin{array}{l}\text { One relevant retail food outlet type offering } \\
\text { foods and/or non-alcoholic beverages e.g. } \\
\text { supermarkets, convenience stores, fast food } \\
\text { restaurants, fresh produce markets (as } \\
\text { retrieved from contextual analysis) }\end{array}$ & $\begin{array}{l}\text { All key retail food outlets: } \\
\text { Supermarkets } \\
\text { Convenience stores } \\
\text { Fast food restaurant chains } \\
\text { Fresh produce markets }\end{array}$ & $\begin{array}{l}\text { Expanded data set plus any other relevant food } \\
\text { outlets, including vending machines }\end{array}$ \\
\hline Dimension of retail food environment & & \\
\hline $\begin{array}{l}\text { Presence/absence of one relevant retail food } \\
\text { outlet type within predefined areas } \\
\text { Density of one relevant retail food outlet type } \\
\text { (count per geographic area/population) } \\
\text { Availability of healthy and unhealthy foods } \\
\text { and beverages in one relevant retail outlet } \\
\text { (e.g. linear shelf space in supermarkets) }\end{array}$ & $\begin{array}{l}\text { Presence/absence of all key retail food outlets } \\
\text { within predefined distance of homes/schools } \\
\text { Density of all key food outlets (as an area or } \\
\text { population average } \pm \text { SD within a specified } \\
\text { buffer around residents' homes and schools or } \\
\text { using the Kernel density method) } \\
\text { Availability and placement (e.g. end-of-aisle and } \\
\text { checkouts) of healthy and unhealthy foods and } \\
\text { beverages in-store for supermarkets and }\end{array}$ & $\begin{array}{l}\text { Expanded data set plus: } \\
\text { Relative density of healthy versus unhealthy food } \\
\text { outlets around homes and schools (as an area } \\
\text { or population average } \pm \text { SD within a specified } \\
\text { buffer around resident's homes and schools or } \\
\text { using the Kernel density method) } \\
\text { Aggregate availability of healthy and unhealthy } \\
\text { foods (cumulative shelf space within predefined } \\
\text { areas) }\end{array}$ \\
\hline
\end{tabular}

Foods

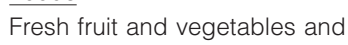
energy-dense, nutrient-poor foods (to be defined depending on local contextual analysis)

Sampling method

Collect data for one to two representative

locations/sites in one geographical area
All fruit and vegetables (fresh, canned, frozen)
and energy-dense, nutrient-poor foods

Collect data for representative locations/sites in an increased number of geographical areas. Include community areas surrounding schools
Expanded data set using a standard approach to food classification based on dietary guidelines to distinguish between healthy and unhealthy options within food categories.

Collect data at multiple representative locations/sites across a broad range of geographically and socioeconomically diverse areas

Analyses

Density of retail food outlets overall and within specific neighbourhoods (e.g. rural/urban, socioeconomic)

Proximity of food outlets to homes/schools (absence/presence within specified distance)

Availability of healthy and unhealthy foods and beverages overall and for specific areas (rural/urban, socioeconomic)

Comparisons between regions, countries and over time

Evaluation of compliance with local policies, guidelines or codes of voluntary practice

SD, standard deviation. 
Table 3 Proposed procedures for monitoring retail food environments

\begin{tabular}{|c|c|c|}
\hline Sampling/time period & Data collection & Measurement indicators \\
\hline $\begin{array}{l}\text { Select representative areas to monitor, } \\
\text { including some with high rates of obesity } \\
\text { and/or poor diets. } \\
\text { Aim to sample geographically (urban/rural) } \\
\text { and socioeconomically (income/ethnicity) } \\
\text { diverse areas. } \\
\text { Include all stores within selected areas for } \\
\text { community food environment measures } \\
\text { Choose a random sample of stores within } \\
\text { each selected area } \\
\text { OR } \\
\text { Select random neighbourhoods within the } \\
\text { selected areas and measure all stores for } \\
\text { consumer food environment measures }\end{array}$ & $\begin{array}{l}\text { Retrieve lists of food outlets via yellow } \\
\text { pages or commercial/online databases } \\
\text { Validate lists of community retail outlets } \\
\text { Geocode data on food outlets, homes and } \\
\text { schools } \\
\text { Specify buffer distances around homes } \\
\text { and schools (Euclidian or along the road } \\
\text { network) } \\
\text { Undertake in-store and in-restaurant audits } \\
\text { of food availability and placement }\end{array}$ & $\begin{array}{l}\text { Relative density of key food retail outlet } \\
\text { types } \\
\text { Cumulative availability of healthy and } \\
\text { unhealthy foods and beverages (integration } \\
\text { of area and in-store measures) } \\
\text { Ratio of store shelf space allocated to } \\
\text { healthy and unhealthy foods and } \\
\text { non-alcoholic beverages } \\
\text { In-store placement of healthy and } \\
\text { unhealthy foods and non-alcoholic } \\
\text { beverages (end of aisles/checkouts) }\end{array}$ \\
\hline
\end{tabular}

\section{Data collection and measurement indicators}

Recommendations for sampling, data collection and measurement indicators are outlined in Table 3. Given wellrecognized disparities in regional and neighbourhood rates of obesity and poor diets, it is recommended that monitoring of the community and consumer retail food environment includes neighbourhoods with high rates of obesity and/or poor diets, and that areas chosen for monitoring be geographically and socioeconomically diverse.

Data collection methods involve retrieval of lists of food outlets via Yellow Pages or local government/commercial databases, geocoding of outlet locations, and in-store audits of food and beverage availability and placement. A set of suggested measurable indicators are included in Table 3. These indicators have been developed based on the literature reviewed in this paper, as well as their utility and relevance from both practical data collection and policy perspectives. Indicators include: relative density of healthy and unhealthy food outlets; cumulative availability of healthy and unhealthy foods and beverages (integration of area-level and in-store measures), and placement of healthy and unhealthy foods and beverages in-store.

\section{Implementation considerations}

The proposed monitoring framework has been designed to facilitate monitoring of the retail food environment in a range of countries, allowing flexibility at the local level. The step-wise approach to data collection is intended to allow all countries, even those with minimal resources, to participate. Some high-income countries will have comprehensive local government databases of existing retail food outlets, and geocoding may already have been undertaken for many regions/neighbourhoods. However, in several countries it is likely that there will be little existing information on retail food outlet availability and accessibility, and new surveys may need to be undertaken. However, even in the absence of geocoding software and expertise, the minimal approach facilitates assessment of presence/ absence and density of key retail food outlet types, and availability of healthy and unhealthy foods and beverages in-store via surveys or audits.

Types of retail food outlets and foods selected for monitoring in each country are likely to vary, and this is likely to create implementation issues that need to be considered. Within countries, a mix of different food outlets may create difficulties in comparing community and consumer food environments. Between countries, different types of food outlets and foods may limit comparability. Groups undertaking monitoring in similar countries could, however, cooperate to ensure that at least some key retail food outlets and foods are investigated in multiple countries to enable analysis of impact in different regions (98).

\section{Links to other modules}

Community and consumer retail food environments encompass a complex range of features likely to impact on food purchases and diets, including availability, accessibility, pricing, promotions and nutritional quality. Approaches to monitoring pricing, promotions and nutritional quality are outlined in INFORMAS modules related to food prices (11), food promotions (68), food labelling (69) and food composition (67).

\section{Conclusion}

The proposed framework to monitor retail food environments provides guidance on methods, data collection procedures and measurement indicators for the availability of healthy and unhealthy foods and non-alcoholic beverages in local food environments. This framework supports the 
development of a consistent system to monitor food environments globally to allow comparisons between regions, jurisdictions and countries, and evaluate the success or failure of policy initiatives to improve local food environments. Monitoring is important to benchmark local food environments, and to promote and guide the development of effective policy interventions. The next step will be to develop standardized protocols for data collection and analysis that can be modified for use by individual countries/regions in order to implement the proposed monitoring framework.

\section{Acknowledgements}

The Rockefeller Foundation kindly supported the work of INFORMAS by hosting the first formal meeting of INFORMAS at the Rockefeller Foundation Bellagio Centre, Italy from 19 to 23 November 2012. The following organizations provided funding support for the travel of participants to Italy for this meeting and the preparation of background research papers: The Rockefeller Foundation, International Obesity Taskforce (IOTF), University of Auckland, Deakin University, The George Institute, University of Sydney, Queensland University of Technology, University of Oxford, University of Pennsylvania Perelman School of Medicine, World Cancer Research Fund International, University of Toronto, and The Australian National University. The Faculty of Health at Deakin University kindly supported the costs for open access availability of this paper, and the Australian National Health and Medical Research Council Centre for Research Excellence in Obesity Policy and Food Systems (APP1041020) supported the coordination and finalizing of INFORMAS manuscripts.

\section{Conflicts of interest}

The authors declare that they have no competing interests.

\section{Supporting information}

Additional Supporting Information may be found in the online version of this paper, http://dx.doi.org/10.1111/ obr. 12080

Table S1. Studies examining relationship between community retail food environments and consumer purchasing behavior.

Table S2. Studies examining relationship between community retail food environments and consumer diets/dietary intake.

Table S3. Studies examining relationship between in-store retail food environments and consumer purchases and diets.
Appendix S1. Monitoring the availability of healthy and unhealthy foods and non-alcoholic beverages in community and consumer retail food environments globally.

\section{References}

1. Feng J, Glass TA, Curriero FC, Stewart WF, Schwartz BS. The built environment and obesity: a systematic review of the epidemiologic evidence. Health Place 2010; 16: 175-190.

2. Holsten J. Obesity and the community food environment: a systematic review. Public Health Nutr 2009; 12: 397-405.

3. Glanz K, Sallis JF, Saelens BE, Frank LD. Healthy nutrition environments: concepts and measures. Am J Health Promot 2005; 19: $330-333$.

4. Hoag C. Los Angeles to vote on fast food ban. The Huffington Post; 2008. [WWW document]. URL http://www.huffingtonpost .com/2008/07/29/los-angeles-to-vote-on-fa_n_115620.html (accessed 30 January 2013).

5. Sturm R, Cohen D. Zoning for health? The year-old ban on new fast-food restaurants in South LA. Health Aff (Millwood) 2009; 28: w1088-w1097.

6. Mair J, Pierce M, Teret S. The use of zoning to restrict fast food outlets: A potential strategy to combat obesity. The Center for Law and the Public's Health at Johns Hopkins \& Georgetown Universities; 2005.

7. Park H. Nutrition policy in South Korea. Asia Pac J Clin Nutr 2008; 17(S1): 343-345.

8. Toronto Food Policy Council. Food strategy update: the mobile good food market; 2013. [WWW document]. URL http://tfpc.to/ initiatives/food-strategy-update-the-mobile-good-food-market (accessed 6 March 2013).

9. San Francisco Government. San Francisco Healthy and Sustainable Food Policy; 2009. [WWW document]. URL http:// www.sfgov3.org/index.aspx?page=754 (accessed 6 March 2013). 10. Swinburn B, Sacks G, Vandevijvere $S$ et al. International Network for Food and Obesity/non-communicable diseases Research, Monitoring and Action Support (INFORMAS): overview and key principles. Obes Rev 2013; 14 (Suppl. 1): 1-12.

11. Lee A, Ni Mhurchu C, Sacks G et al. Monitoring the price and affordability of foods and diets globally. Obes Rev 2013; 14 (Suppl. 1): 108-119.

12. Caspi C, Sorensen G, Subramanian S, Kawachi I. The local food environment and diet: a systematic review. Health Place 2012; 18: 1172-1187.

13. Fleischhacker S, Evenson K, Rodriguez D, Ammerman A. A systematic review of fast food access studies. Obes Rev 2011; 12 : e460-e471.

14. D’Angelo H, Suratkar S, Song H, Stauffer E, Gittelsohn J. Access to food source and food source use are associated with healthy and unhealthy food-purchasing behaviours among lowincome African-American adults in Baltimore City. Public Health Nutr 2011; 14: 1632-1639.

15. He M, Tucker P, Gilliland J, Irwin J, Larsen K, Hess P. The influence of local food environments on adolescents' food purchasing behaviors. Int J Environ Res Public Health 2012; 9: 14581471.

16. Hearst M, Pasch K, Laska M. Urban v. suburban perceptions of the neighbourhood food environment as correlates of adolescent food purchasing. Public Health Nutr 2012; 15: 299-306.

17. Laska M, Hearst M, Forsyth A, Pasch K, Lytle L. Neighbourhood food environments: are they associated with adolescent dietary intake, food purchases and weight status? Public Health Nutr 2010; 13: 1757-1763. 
18. Mason K, Bentley R, Kavanagh A. Fruit and vegetable purchasing and the relative density of healthy and unhealthy food stores: evidence from an Australian multilevel study. J Epidemiol Community Health 2013; 67: 231-236.

19. Thornton L, Bentley R, Kavanagh A. Fast food purchasing and access to fast food restaurants: a multilevel analysis of VicLANES. Int J Behav Nutr Phys Act 2009; 6: 28.

20. Thornton L, Kavanagh A. Association between fast food purchasing and the local food environment. Nutr Diabetes 2012; 2: e53.

21. Giskes K, Kamphuis CBM, Van Lenthe FJ, Kremers S, Droomers M, Brug J. A systematic review of associations between environmental factors, energy and fat intakes among adults: is there evidence for environments that encourage obesogenic dietary intakes? Public Health Nutr 2007; 10: 1005-1017.

22. van der Horst K, Timperio A, Crawford D, Roberts R, Brug J, Oenema A. The school food environment associations with adolescent soft drink and snack consumption. Am J Prev Med 2008; 35: 217-223.

23. Cummins S, Petticrew M, Higgins C, Findlay A, Sparks L. Large scale food retailing as an intervention for diet and health: quasi-experimental evaluation of a natural experiment. $J$ Epidemiol Community Health 2005; 59: 1035-1040.

24. Wrigley N, Warm D, Margetts B. Deprivation, diet and foodretail access: findings from the Leeds 'food deserts' study. Environ Plann A 2003; 35: 151-188.

25. An R, Sturm R. School and residential neighborhood food environment and diet among California youth. Am J Prev Med 2012; 42: 129-135.

26. Boone-Heinonen J, Gordon-Larsen P, Kiefe C, Shikany J, Lewis C, Popkin B. Fast food restaurants and food stores: longitudinal associations with diet in young to middle-aged adults: the CARDIA study. Arch Intern Med 2011; 171: 1162 1170 .

27. Caspi C, Kawachi I, Subramanian S, Adamkiewicz G, Sorensen G. The relationship between diet and perceived and objective access to supermarkets among low-income housing residents. Soc Sci Med 2012; 75: 1254-1262.

28. Charreire H, Kesse-Guyot E, Simon C et al. Spatial accessibility to food outlets, fruits and vegetables consumption and weight status in French adults. Obes Facts 2012; 5 (Suppl. 1): 18.

29. Dean W, Sharkey J. Rural and urban differences in the associations between characteristics of the community food environment and fruit and vegetable intake. J Nutr Educ Behav 2011; 43 : 426-433.

30. Forsyth A, Wall M, Larson N, Story M, Neumark-Sztainer D. Do adolescents who live or go to school near fast-food restaurants eat more frequently from fast-food restaurants? Health Place 2012; 18: 1261-1269.

31. Fuller D, Cummins S, Matthews S. Does transportation mode modify associations between distance to food store, fruit and vegetable consumption, and BMI in low-income neighborhoods? Am J Clin Nutr 2013; 97: 167-172.

32. He M, Tucker P, Irwin J, Gilliland J, Larsen K, Hess P. Obesogenic neighbourhoods: the impact of neighbourhood restaurants and convenience stores on adolescents' food consumption behaviours. Public Health Nutr 2012; 15: 2331-2339.

33. Heroux M, Iannotti R, Currie D, Pickett W, Janssen I. The food retail environment in school neighborhoods and its relation to lunchtime eating behaviors in youth from three countries. Health Place 2012; 18: 1240-1247.

34. Jaime P, Duran A, Sarti F, Lock K. Investigating environmental determinants of diet, physical activity, and overweight among adults in Sao Paulo, Brazil. J Urban Health 2011; 88: 567-581.
35. Layte R, Harrington J, Sexton E, Perry I, Cullinan J, Lyons S. Irish exceptionalism? Local food environments and dietary quality. J Epidemiol Community Health 2011; 65: 881-888.

36. MacDonald L, Ellaway A, Ball K, Macintyre S. Is proximity to a food retail store associated with diet and BMI in Glasgow, Scotland? BMC Public Health 2011; 11: 464.

37. Murakami K, Sasaki S, Takahashi Y, Uenishi K. Neighborhood restaurant availability and frequency of eating out in relation to dietary intake in young Japanese women. J Nutr Sci Vitaminol (Tokyo) 2011; 57: 87-94.

38. Ollberding N, Nigg C, Geller K, Horwath C, Motl R, Dishman R. Food outlet accessibility and fruit and vegetable consumption. Am J Health Promot 2012; 26: 366-370.

39. Richardson A, Boone-Heinonen J, Popkin B, Gordon-Larsen P. Neighborhood fast food restaurants and fast food consumption: a national study. BMC Public Health 2011; 11: 543.

40. Richmond T, Spadano-Gasbarro J, Walls C et al. Density of food outlets does not explain individual racial/ethnic or betweenschool differences in sugar-sweetened beverage consumption. Obesity 2011; 19: S143.

41. Sharkey J, Johnson C, Dean W, Horel S. Association between proximity to and coverage of traditional fast-food restaurants and non-traditional fast-food outlets and fast-food consumption among rural adults. Int J Health Geogr 2011; 10: 37.

42. Thornton L, Pearce J, Macdonald L, Lamb K, Ellaway A. Does the choice of neighbourhood supermarket access measure influence associations with individual-level fruit and vegetable consumption? A case study from Glasgow. Int J Health Geogr 2012; 11: 29 .

43. Wang R, Shi L. Access to food outlets and children's nutritional intake in urban China: a difference-in-difference analysis. Ital J Pediatr 2012; 38: 30.

44. Leung C, Gregorich S, Laraia B, Kushi L, Yen I. Measuring the neighborhood environment: associations with young girls' energy intake and expenditure in a cross-sectional study. Int J Behav Nutr Phys Act 2010; 7: 52.

45. Rose D, Richards R. Food store access and household fruit and vegetable use among participants in the US Food Stamp Program. Public Health Nutr 2004; 7: 1081-1088.

46. Zenk S, Schulz A, Hollis-Neely $\mathrm{T}$ et al. Fruit and vegetable intake in African Americans income and store characteristics. Am J Prev Med 2005; 29: 1-9.

47. Sharkey J, Johnson C, Dean W. Food access and perceptions of the community and household food environment as correlates of fruit and vegetable intake among rural seniors. BMC Geriatr 2010; 10: 32.

48. Charreire H, Casey R, Salze P et al. Measuring the food environment using geographical information systems: a methodological review. Public Health Nutr 2010; 13: 1773-1785.

49. Thornton L, Pearce J, Kavanagh A. Using geographic information systems (GIS) to assess the role of the built environment in influencing obesity: a glossary. Int J Behav Nutr Phys Act 2011; 8: 71.

50. Bodor J, Rose D, Farley T, Swalm C, Scott S. Neighbourhood fruit and vegetable availability and consumption: the role of small food stores in an urban environment. Public Health Nutr 2008; 11: 413-420.

51. Jeffery RW, Baxter JE, McGuire MT, Linde JA. Are fast food restaurants an environmental risk factor for obesity? Int J Behav Nutr Phys Act 2006; 3: 2.

52. Christian W. Using geospatial technologies to explore activitybased retail food environments. Spat Spatio-temporal Epidemiol 2012; 3: 287-295. 
53. Apparicio P, Abdelmajid M, Riva M, Shearmur R. Comparing alternative approaches to measuring the geographical accessibility of urban health services: distance types and aggregation-error issues. Int J Health Geogr 2008; 7: 7.

54. Lovett A, Haynes R, Sunnenberg G, Gale S. Car travel time and accessibility by bus to general practitioner services: a study using patient registers and GIS. Soc Sci Med 2002; 55: 97-111.

55. Sharkey J. Measuring potential access to food stores and foodservice places in rural areas in the U.S. Am J Prev Med 2009; 36: S151-S155.

56. Hillier A, Cannuscio C, Karpyn A. How far do low-income parents travel to shop for food? Empirical evidence from two urban neighborhoods. Urban Geogr 2011; 32: 712-729.

57. Jennings A, Welch A, Jones A et al. Local food outlets, weight status, and dietary intake: associations in children aged 9-10 years. Am J Prev Med 2011; 40: 405-410.

58. Turrell G, Giskes K. Socioeconomic disadvantage and the purchase of takeaway food: a multilevel analysis. Appetite 2008; 51: 69-81.

59. Liese A, Colabianchi N, Lamichhane A et al. Validation of 3 food outlet databases: completeness and geospatial accuracy in rural and urban food environments. Am J Epidemiol 2010; 172: 1324-1333.

60. Powell L, Han E, Zenk S et al. Field validation of secondary commercial data sources on the retail food outlet environment in the U.S. Health Place 2011; 17: 1122-1131.

61. Bader M, Ailshire J, Morenoff J, House J. Measurement of the local food environment: a comparison of existing data sources. Am J Epidemiol 2010; 171: 609-617.

62. Boone J, Gordon-Larsen P, Stewart J, Popkin B. Validation of a GIS facilities database: quantification and implications of error. Ann Epidemiol 2008; 18: 371-377.

63. Hay G, Kypri K, Whigham P, Langley J. Potential biases due to geocoding error in spatial analyses of official data. Health Place 2009; 15: 562-567.

64. Porter D, Kirtland K, Neet M, Williams J, Ainsworth B. Considerations for using a geographic information system to assess environmental supports for physical activity. Prev Chronic Dis 2004; 1: A20.

65. Cummins S, Macintyre S. A systematic study of an urban foodscape: the price and availability of food in greater Glagow. Urban Stud 2002; 39: 2115.

66. McCarthy J. Basic Marketing: A Managerial Approach, 13th edn. Homewoon Illinois: Irwin, 2001.

67. Neal B, Sacks G, Swinburn B et al. Monitoring the levels of important nutrients in the food supply. Obes Rev 2013; 14 (Suppl. 1): 49-58.

68. Kelly B, King L, Baur L et al. Monitoring food and non-alcoholic beverage promotions to children. Obes Rev 2013; 14 (Suppl. 1): 59-69.

69. Rayner M, Wood AT, Lawrence M et al. Monitoring the health-related labelling of foods and non-alcoholic beverages in retail settings. Obes Rev 2013; 14 (Suppl. 1): 82-95.

70. Glanz K, Bader M, Iyer S. Retail grocery store marketing strategies and obesity: an integrative review. Am J Prev Med 2012; 42: 503-512.

71. Gustafson A, Hankins S, Jilcott S. Measures of the consumer food store environment: a systematic review of the evidence 20002011. J Community Health 2012; 37: 897-911.

72. Hawkes C. Dietary implications of supermarket development: a global perspective. Dev Policy Rev 2008; 26: 657-692.

73. Kerr J, Frank L, Sallis J, Saelens B, Glanz K, Chapman J. Predictors of trips to food destinations. Int J Behav Nutr Phys Act 2012; 9: 58.
74. Miller C, Bodor J, Rose D. Measuring the food environment: a systematic technique for characterizing food stores using display counts. J Environ Public Health 2012; 2012: 707860. doi: 10.1155/2012/707860.

75. Casagrande S, Whitt-Glover M, Lancaster K, Odoms-Young A, Gary T. Built environment and health behaviors among African Americans: a systematic review. Am J Prev Med 2009; 36: 174 181.

76. Gustafson A, Sharkey J, Samuel-Hodge C et al. Perceived and objective measures of the food store environment and the association with weight and diet among low-income women in North Carolina. Public Health Nutr 2011; 14: 1032-1038.

77. Hermstad AK, Swan DW, Kegler MC, Barnette JK, Glanz K. Individual and environmental correlates of dietary fat intake in rural communities: a structural equation model analysis. Soc $S_{c i}$ Med 2010; 71: 93-101.

78. Thornton L, Crawford D, Ball K. Neighbourhoodsocioeconomic variation in women's diet: the role of nutrition environments. Eur J Clin Nutr 2010; 64: 1423-1432.

79. Franco M, Diez-Roux A, Nettleton J et al. Availability of healthy foods and dietary patterns: the Multi-Ethnic Study of Atherosclerosis. Am J Clin Nutr 2009; 89: 897-904.

80. Cheadle A, Psaty BM, Curry S et al. Can measures of the grocery store environment be used to track community-level dietary changes? Prev Med 1993; 22: 361-372.

81. Cheadle A, Psaty BM, Diehr P et al. Evaluating communitybased nutrition programs: comparing grocery store and individual level survey measures of program impact. Prev Med 1995; 24 : 71-79.

82. Curhan R. The relationship between shelf space and unit sales in supermarkets. J Mark Res 1972; 9: 406-412.

83. Curhan R. The effects of merchandising and temporary promotional activities on the sales of fresh fruits and vegetables in supermarkets. J Mark Res 1974; 11: 286-294.

84. Farley T, Rice J, Bodor J, Cohen D, Bluthenthal R, Rose D. Measuring the food environment: shelf space of fruits, vegetables, and snack foods in stores. J Urban Health 2009; 86: 672-682.

85. Gittelsohn J, Vijayadeva V, Davison N et al. A food store intervention trial improves caregiver psychosocial factors and children's dietary intake in Hawaii. Obesity 2010; 18(Suppl. 1): S84-S90.

86. Hansen P, Heinsbroek H. Product selection and space allocation in supermarkets. Eur J Oper Res 1979; 3: 474-484.

87. Inman J, Winer R, Ferraro R. The interplay among category characteristics, customer characteristics, and customer activities on in-store decision making. J Mark 2009; 73: 19-29.

88. Kerr J, Sallis J, Bromby E, Glanz K. Assessing reliability and validity of the GroPromo audit tool for evaluation of grocery store marketing and promotional environments. J Nutr Educ Behav 2012; 44: 597-603.

89. Reedy J, Krebs-Smith S, Bosire C. Evaluating the food environment. Application of the Healthy Eating Index-2005. Am J Prev Med 2010; 38: 465-471.

90. Rose D, Hutchinson P, Bodor J et al. Neighborhood food environments and body mass index: the importance of in-store contents. Am J Prev Med 2009; 37: 214-219.

91. Sharkey J, Dean W, Nalty C. Convenience stores and the marketing of foods and beverages through product assortment. Am J Prev Med 2012; 43(Suppl. 2): S109-S115.

92. Sorensen H. The science of shopping. Mark Res 2003; 48: 329-338.

93. Wilkinson J, Mason J, Paksoy C. Assessing the impact of short-term supermarket strategy variables. J Mark Res 1982; 19: 72-86. 
94. Thornton L, Cameron A, Crawford D, McNaughton S, Ball K. Is greater variety of chocolates and confectionery in supermarkets associated with more consumption? Aust N Z J Public Health 2011; 35: 292-293.

95. Glanz K, Sallis J, Saelens B, Frank L. Nutrition Environment Measures Survey in Stores (NEMS-S). Am J Prev Med 2007; 32: 282-289.

96. Cameron A, Thornton L, McNaughton S, Crawford D. Variation in supermarket exposure to energy-dense snack foods by socioeconomic position. Public Health Nutr 2013; 16: 11781185 .

97. Thornton L, Cameron A, McNaughton S, Worsley A, Crawford D. The availability of snack food displays that may trigger impulse purchases in Melbourne supermarkets. BMC Public Health 2012; 12: 194.

98. Thornton L, Cameron A, McNaughton S et al. Does the availability of snack foods in supermarkets vary internationally? Int J Behav Nutr Phys Act 2013; 10: 56.

99. Saelens BE, Glanz K, Sallis JF, Frank LD. Nutrition Environment Measures Study in restaurants (NEMS-R): development and evaluation. Am J Prev Med 2007; 32: 273-281.

100. Lewis LB, Sloane DC, Nascimento LM et al. African Americans' access to healthy food options in South Los Angeles restaurants. Am J Public Health 2005; 95: 668-673.

101. Lock K, Pomerleau J, Causer L, Altmann DR, McKee M. The global burden of disease attributable to low consumption of fruit and vegetables: implications for the global strategy on diet. Bull World Health Organ 2005; 83: 100-108.

102. de Ruyter JC, Olthof MR, Seidell JC, Katan MB. A trial of sugar-free or sugar-sweetened beverages and body weight in children. N Engl J Med 2012; 367: 1397-1406.

103. Rangan AM, Randall D, Hector DJ, Gill TP, Webb KL. Consumption of 'extra' foods by Australian children: types, quantities and contribution to energy and nutrient intakes. Eur J Clin Nutr 2007; 62: 356-364.

104. Jaworowska A, Blackham T, Davies IG, Stevenson L. Nutritional challenges and health implications of takeaway and fast food. Nutr Rev 2013; 71: 310-318.

105. Handy S, Cao X, Mokhtarian P. Self-selection in the relationship between the built environment and walking. J Am Plann Assoc 2006; 72: 55-74.

106. Kloog I, Haim A, Portnov B. Using kernel density function as an urban analysis tool: investigating the association between nightlight exposure and the incidence of breast cancer in Haifa, Israel. Comput Environ Urban Syst 2009; 33: 5563.

107. Pearson T, Russell J, Campbell M, Barker M. Do 'food deserts' influence fruit and vegetable consumption? - A crosssectional study. Appetite 2005; 45: 195-197.

108. Walker R, Keane C, Burke J. Disparities and access to healthy food in the United States: a review of food deserts literature. Health Place 2010; 16: 876-884. 